\title{
Genome-wide identification and expression analysis of the WRKY genes in sugar beet (Beta vulgaris L.) under alkaline stress
}

\author{
Guo-Qiang Wu ${ }^{\text {Corresp., }}{ }^{,}$, Zhi-Qiang $\mathbf{L i}^{1}{ }^{1}$, Han Cao ${ }^{1}$, Jin-Long Wang ${ }^{1}$ \\ ${ }^{1}$ School of Life Science and Engineering, Lanzhou University of Technology, Lanzhou, China \\ Corresponding Author: Guo-Qiang Wu \\ Email address: gqwu@lut.cn
}

Background: The WRKY transcription factor family plays crucial roles in many aspects of physiological processes and adaption to environment. Although the WRKY genes have been widely identified in various plant species, the structure and function of the WRKY family in sugar beet (Beta vulgaris L.) remains unknown.

Methods: In the present study, the WRKY genes were identified from the sugar beet genome by bioinformatics. Phylogenetic tree was constructed by MEGA7.0. Distribution map of these genes was displayed b Maplnspect 1.0. Furthermore, the exon-intron structure and the conserved motifs were predicted by GSDS 2.0 and MEME 5.0.5, respectively. Additionally, the expression levels of 9 selected genes in shoots and roots of sugar beet seedlings exposed to alkaline stress were assayed by qRT-PCR.

Results: A total of 58 putative BVWRKY genes are identified in the sugar beet genome. The coding sequences of these genes ranged from 558 to 2,307 bp and molecular weights (MWs) varied from 21.3 to 84. The BVWRKY genes are clustered into three major groups I, II and III, with 11, 40 and 7 members, based on the primary amino acid sequences. The number of introns in the BVWRKY genes ranged from 1 to 5, with a majority of BvWRKY (27/58) containing three exons. All the BvWRKY genes have one or two conserved WRKY domains and zinc-finger structure. Moreover, the selected $B V W R K Y$ genes showed a variety of expression patterns in shoots and roots of seedlings under various concentrations of $\mathrm{NaHCO}_{3}$. Importantly, BVWRKY10 in shoots and BVWRKY16 in roots were remarkably up-regulated by alkaline stress. Taken together, our findings extend understandings of the BVWRKY genes family and provide useful information for subsequent research on their functions in sugar beet under alkaline stress. 
1 Genome-wide identification and expression analysis of the $W R K Y$ genes in sugar beet (Beta

2 vulgaris $\mathrm{L}$.$) under alkaline stress$

3

4 Guo-Qiang Wu${ }^{1}$, Zhi-Qiang $\mathrm{Li}^{1}$, Han $\mathrm{Cao}^{1}$, Jin-Long Wang ${ }^{1}$

5

$6{ }^{1}$ School of Life Science and Engineering, Lanzhou University of Technology, Lanzhou 730050,

7 China

8

9 Corresponding Author:

10 Guo-Qiang $\mathrm{Wu}^{1}$

11287 Langongping Road, Lanzhou 730050, China

12 E-mail: gqwu@,lut.cn

13

14

15

16

17

18

19

20

21

22

23 


\section{ABSTRACT}

Background: The WRKY transcription factor family plays crucial roles in many aspects of physiological processes and adaption to environment. Although the $W R K Y$ genes have been widely identified in various plant species, the structure and function of the $W R K Y$ family in sugar beet (Beta vulgaris L.) remains unknown.

Methods: In the present study, the $W R K Y$ genes were identified from the sugar beet genome by bioinformatics. Phylogenetic tree was constructed by MEGA7.0. Distribution map of these genes was displayed by MapInspect 1.0. Furthermore, the exon-intron structure and the conserved motifs were predicted by GSDS 2.0 and MEME 5.0.5, respectively. Additionally, the expression levels of 9 selected genes in shoots and roots of sugar beet seedlings exposed to alkaline stress were assayed by qRT-PCR.

Results: A total of 58 putative $B v W R K Y$ genes are identified in the sugar beet genome. The coding sequences of these genes ranged from 558 to 2,307 bp and molecular weights (MWs) varied from 21.3 to 84 . The $B v W R K Y$ genes are clustered into three major groups I, II and III, with 11, 40 and 7 members, based on the primary amino acid sequences. The number of introns in the $B v W R K Y$ genes ranged from 1 to 5, with a majority of $B v W R K Y(27 / 58)$ containing three exons. All the $B v W R K Y$ genes have one or two conserved WRKY domains and zinc-finger structure. Moreover, the selected $B v W R K Y$ genes showed a variety of expression patterns in shoots and roots of seedlings under various concentrations of $\mathrm{NaHCO}_{3}$. Importantly, $B v W R K Y 10$ in shoots and $B v W R K Y 16$ in roots were remarkably up-regulated by alkaline stress. Taken together, our findings extend understandings of the $B v W R K Y$ genes family and provide useful information for subsequent research on their functions in sugar beet under alkaline stress.

Keywords: Sugar beet, WRKY transcription factor, Bioinformatics, Alkaline stress, Expression levels 


\section{INTRODUCTION}

Plants encounter various abiotic and biotic stresses throughout their life cycle. These stresses can adversely affect the growth and development of plants and/or change the distribution of species (Prachi et al., 2017). To cope with these adverse environmental conditions, plants have evolved a variety of mechanisms at the morphological, physiological, cellular and molecular levels during the process of long-term evolution (Hasanuzzaman et al., 2013; Bechtold et al., 2017; Yang \& Guo, 2018). To date, the responses of abiotic stresses and the regulation of genes have been widely identified in various plant species, such as Arabidopsis thaliana (Kotchoni et al., 2006), rice (Oryza sativa) (Lee et al., 2005), tomato (Lycopersicon esculentum) (Sharma et al., 2010), and wheat (Triticum aestivum) (Zhang et al., 2011). It is well-documented that several families of genes are particularly related to obvious improvement in abiotic stress tolerance of plants, including the $W R K Y, N A C, M Y B$, and $G R F$ genes families (Chinnusamy, Zhu \& Zhu, 2006; Hennig, 2012; Cao et al., 2017; Khadiza et al., 2017).

WRKY proteins are a large family of transcription factors (TFs) involved in various aspects of physiological processes as well as responded to biotic and abiotic stresses (Jiang et al., 2016). Since the first WRKY gene SPF1 was cloned from sweetpotato (Ipomoea batatas) (Ishiguro \& Nakamura, 1994), more and more $W R K Y$ genes have been identified in various plant species, especially some grass species, including barley (Hordeum vulgare) (Mangelsen et al., 2008), Brachypodium distachyon (Wen et al., 2014), maize (Zea mays) (Wei et al., 2016), rice (Ross, Liu \& Shen, 2010), and wheat (Zhu et al., 2013). All the members of the WRKY genes have been documented to have one or two conserved WRKY domains, which are composed of approximately 60 amino acids with "WRKYGQK" at N-terminus and a novel zinc-finger motif $\mathrm{C}-\mathrm{X}_{4-5}-\mathrm{C}-\mathrm{X}_{22-23}-\mathrm{H}-\mathrm{X}-\mathrm{H}\left(\mathrm{C}_{2} \mathrm{H}_{2}\right)$ or $\mathrm{C}-\mathrm{X}_{7}-\mathrm{C}-\mathrm{X}_{23}-\mathrm{H}-\mathrm{X}-\mathrm{C}\left(\mathrm{C}_{2} \mathrm{HC}\right)$ at C-terminus (Eulgem et al., 2000; Rushton et al., 2010). Based on the number and characteristics of the conserved WRKY domains, the $W R K Y$ genes were clustered into three groups I, II, and III (Eulgem et al., 2000). There are evidences that the WRKY members of group I displayed two WRKY domains with zinc-finger motifs of $\mathrm{C}_{2} \mathrm{H}_{2}$, group II contained only single WRKY domain with a zinc-finger motif of $\mathrm{C}_{2} \mathrm{H}_{2}$, whereas group III had one WRKY domain with a zinc-finger motif of $\mathrm{C}_{2} \mathrm{HC}$ (Rushton et al., 2010). Additionally, the WRKYs of group II can be further classified into five distinct subgroups IIa-e (Rushton et al., 2010; Ulker \& Somssich, 2004). It was also reported that the $W R K Y$ genes were significantly induced by various environmental factors, such as heat 
89 (Li et al., 2009), drought (Jiang, Gang \& Yu, 2012), waterlogging (Li et al., 2017), cold (Luo et al., 2017), and salt (Dan et al., 2018), indicating that the WRKY genes play the positive regulatory functions in plants when exposed to adversely stressed conditions. In Arabidopsis, overexpression of TaWRKY1 and TaWRKY33 from wheat has been shown to activate the expression of several downstream genes related to stress response, increase the germination rate of seeds, and promote the growth of roots in transgenic plants subjected to various stresses (He et al., 2016). Compared to wild-type (WT) lines, TaWRKY33 transgenic Arabidopsis lines displayed lower rates of water loss during dehydration (He et al., 2016). In rice, OsWRKY72 conferred more tolerant to salt and drought stresses via ABA signaling (Song et al., 2009). OsWRKY74 overexpressing rice exhibited greater accumulation of iron (Fe) and up-regulation of the cold-responsive genes compared with WT plants in P-deficient conditions (Dai, Wang \& Zhang, 2016). Under saline condition, the activities of catalase (CAT), peroxidase (POD), and superoxide dismutase (SOD) in Chrysanthemum overexpressed DgWRKY5 gene were significantly higher than those of WT plants, whilst the accumulation of $\mathrm{H}_{2} \mathrm{O}_{2}, \mathrm{O}^{2-}$, and malondialdehyde (MDA) were significantly lower than those of WT plants (Liang et al., 2017). Moreover, the expression levels of genes related stress such as $D g C A T, D g A P X, D g N C E D 3 A$, $D g C u Z n S O D, D g N C E D 3 B, D g C S D 1, D g C S D 2$, and $D g P 5 C S$ were remarkably higher in transgenic Chrysanthemum plants than those in WT plants, indicating that DgWRKY5 might be a positive regulatory factor in response to salt stress (Liang et al., 2017). These results documented that the $W R K Y$ genes may provide valuable insights into abiotic stress tolerance mechanisms in plants.

Sugar beet $(2 n=18$, Beta vulgaris L.), belonging to the order of Caryophyalles, is a major sugar crop worldwide, which provides approximately 30\% of the world's sugar production (Liu et al., 2010). In China, this crop is cultivated in the arid and semi-arid regions of Northern China (Wu et al., 2013). The whole-genome sequence of sugar beet was completed and released in 2014 and a total of $359.14 \mathrm{Mb}$ of sequence data were assembled with 27,421 protein-coding genes predicted (Dohm et al., 2014). Our previous studies indicated that the addition of $50 \mathrm{mM}$ $\mathrm{NaCl}$ in the growth medium can stimulate the growth of plants and mitigate the damage caused by osmotic stress in sugar beet (Wu et al., 2015). Recently, our results showed that $\mathrm{Na}^{+}$ concentrations in roots and shoots displayed a sharply increased trend with the increase of $\mathrm{NaCHO}_{3}$ concentrations, whereas $\mathrm{K}^{+}$concentrations maintained a relatively stable level under 
120 either low- or high-alkaline conditions (Dataset S1). These results implied that the maintenance

121 of $\mathrm{K}^{+}$and $\mathrm{Na}^{+}$homeostasis might be an important strategy for sugar beet adapting to alkaline

122

123

124

125

126

127

128

129

130

131

132

133

134

135

136

137

138

139

140

141

142

143

144

145

146

147

148

149

150

stress. However, the WRKY family genes and their regulated expression in sugar beet exposed to alkaline stress still remain unknown.

Here, we proposed a hypothesis that the $W R K Y$ genes play a positive regulatory function in response to alkaline stress in sugar beet. To test this hypothesis, in this study, firstly, a total of 58 $B v W R K Y$ genes were identified in the sugar beet genome, and the phylogenetic relationship, chromosome distribution, genes structure and conserved motifs were analyzed; Secondly, the expression patterns of the $B v W R K Y$ genes in roots and shoots of sugar beet seedlings exposed to different concentrations $(15-100 \mathrm{mM})$ of $\mathrm{NaCHO}_{3}$ were determined by qRT-PCR. Our findings extend understandings of the $B v W R K Y$ family genes and provide useful information for subsequent research on their functions in sugar beet under alkaline stress.

\section{MATERIALS AND METHODS}

\section{Identification and distribution of the WRKY genes in sugar beet}

To identify the sugar beet $W R K Y$ family genes, protein sequences of the $W R K Y$ genes in Arabidopsis were downloaded from the Arabidopsis Information Resource (TAIR) (https://www.arabidopsis.org/), and used queries in performing on Basic Local Alignment Search Tool of protein (BLASTp) searches with default algorithm parameters on the Beta vulgaris Resource (http://bvseq.boku.ac.at/) (Dohm et al., 2014) and NCBI sugar beet genome data (https://www.ncbi.nlm.nih.gov/nuccore/?term=Beta+vulgaris+subsp.+vulgaris). The hidden Markov Model (HMM) profiles of the conserved WRKYGQK domain PF03106 were obtained from Pfam 32.0 (http://pfam.xfam.org/) and the HMM 3.1 search tool (https://www.ebi.ac.uk/Tools/hmmer/) was used to identify all WRKY proteins in sugar beet (Potter et al., 2018). Candidate WRKY proteins were manually further validate (Wang et al., 2014) via searching for WRKY domains in the amino acid sequences using online tool SWISSMODEL (https://swissmodel.expasy.org/) (Benkert, Biasini \& Schwede, 2011). Redundant and incomplete residual sequences were removed from protein sequences with complete WRKYGQK domains by using DNAMAN 6.0 (Yue et al., 2019).

The isoelectric points (pIs) and theoretical molecular weights (MWs) of each BvWRKY protein were predicted online at https://web.expasy.org/protparam/ (Gasteiger et al., 2005). Based on the position information from the sugar beet genome database, the $B v W R K Y$ genes 
151

152

153

154

155

156

157

158

159

were plotted on the chromosomes and the distribution map of $B v W R K Y$ genes was displayed by MapInspect 1.0 (https://mapinspect.software.informer.com/). Tandem and segmental duplication events of $B v W R K Y$ genes analyzed according to the methods as described by Hu \& Liu (2012).

\section{Phylogenetic analysis, gene structure and conserved motifs distribution}

The amino acid sequences of $B v W R K Y$ genes were aligned with those of $A t W R K Y s$ from Arabidopsis (Supplementary Table S1), by using the Clustal W 2.0 (http://www.clustal.org/clustal2/) (Larkin et al., 2007). Phylogenetic tree was constructed by MEGA 7.0 (https://www.megasoftware.net/) using the neighbor-joining (NJ) algorithm with 1,000 bootstraps. The exon-intron structures of the $B v W R K Y$ genes were predicated via Gene Structure Display Server (GSDS 2.0, http://gsds.cbi.pku.edu.cn/) according to the alignments of their coding sequences (CDS) with their corresponding genomic sequences (Hu et al., 2015). Multiple Em for Motif Elicitation (MEME 5.0.5, http://meme-suite.org/tools/meme) was used to predict the conserved motifs of the BvWRKY genes (Bailey \& Elkan, 1994), and the parameters used in this study were set as follows: maximum number of different motifs is 10 , other default parameters.

\section{Gene ontology analysis}

Gene ontology (GO) terms of $B v W R K Y s$ were predicted by using online tool DAVID Bioinformatics Resources 6.8 (https://david.ncifcrf.gov/home.jsp) (Huang, Sherman \& Lempicki, 2009). The analysis was based mainly on three aspects: cellular component, biological processes, and molecular function.

\section{Three-dimensional structure analysis of BvWRKY}

The three-dimensional (3D) structures of nine selected proteins, namely BvWRKY3, -10, $16,-22,-41,-42,-44,-47$, and -51 , were predicted by online service I-TASSER (https://zhanglab.ccmb.med.umich.edu/I-TASSER/) (Yang et al., 2015). In order to identify structurally similar templates in the Protein Data Bank (PDB) database (Berman et al., 2000), the query sequences were subjected to multiple rounds of threading using the LOMETS method (Zheng et al., 2019).

\section{Plant materials, growth conditions and alkaline stress treatments}

Seeds of sugar beet (B. vulgaris L.) cultivar "Gantang7" were kindly provided by Wuwei Sannong Seed Technology Co., Ltd., Gansu, China, in May 2018. Seeds were surface sterilized 
181 for $1 \mathrm{~min}$ in $75 \%$ ethanol $(v / v)$ and rinsed three times with sterilized distilled water, soaked in

182 sterilized water for $24 \mathrm{~h}$ (Wu et al., 2013; 2015), and then planted in plastic containers filled with vermiculite and watered with the modified Hoagland nutrient solution including $2 \mathrm{mM} \mathrm{KNO}_{3}, 1$ $\mathrm{mM} \mathrm{NH} \mathrm{H}_{2} \mathrm{PO}_{4}, 0.5 \mathrm{mM} \mathrm{Ca}\left(\mathrm{NO}_{3}\right)_{2}, 18 \mathrm{mM} \mathrm{MnCl}_{2} \cdot 4 \mathrm{H}_{2} \mathrm{O}, 1.6 \mathrm{mM} \mathrm{ZnSO}_{4} \cdot 7 \mathrm{H}_{2} \mathrm{O}, 0.6 \mathrm{mM}$ $\mathrm{CuSO}_{4} \cdot 5 \mathrm{H}_{2} \mathrm{O}, 0.5 \mathrm{mM} \mathrm{MgSO}_{4}, 60 \mathrm{mM}$ Fe-Citrate, $92 \mathrm{mM} \mathrm{H}_{3} \mathrm{BO}_{3}$, and $0.7 \mathrm{mM}$ $\left(\mathrm{NH}_{4}\right)_{6} \mathrm{Mo}_{7} \mathrm{O}_{24} \cdot 4 \mathrm{H}_{2} \mathrm{O}$. All the seedlings were grown in the same growth chamber at temperature of $25 / 20{ }^{\circ} \mathrm{C}$ (day/night), daily photoperiod of $16 / 8 \mathrm{~h}$ (day/night), relative humidity of $65-75 \%$, and light density of $550-600 \mathrm{mmol} \cdot \mathrm{m}^{-2} \cdot \mathrm{s}^{-1}$ during the photoperiod.

Four-week-old seedlings with uniform size were subjected with the modified Hoagland nutrient solution supplemented with additional $0,15,25,50$, and $100 \mathrm{mM} \mathrm{NaHCO}_{3}$. Shoot and root tissues were collected at $72 \mathrm{~h}$ after $\mathrm{NaHCO}_{3}$ treatments, respectively. Samples of shoots and roots were immediately frozen in liquid nitrogen and stored at $-80^{\circ} \mathrm{C}$ until RNA extraction.

\section{qRT-PCR analysis}

To validate functions of $B v W R K Y s$ in response to alkaline stress, nine genes, including 5 genes in group I ( $B v W R K Y 10,-22,-41,-44$, and -51$)$ and 4 genes in group II (BvWRKY3, -16, 42, and -47), were selected according to homologous genes in rice and Arabidopsis (Wu et al., 2005), and their expression patterns were analyzed by using qRT-PCR. The total RNA was isolated from roots or shoots of sugar beet using UNIQ-10 Column Trizol Total RNA Isolation kit (Sangon, Shanghai, China) according to the manufacturer's procedure. The cDNAs were synthesized using a PrimeScript ${ }^{\mathrm{TM}}$ Real-Time (RT) Master Mix kit (Takara, Dalian, China) according to the manufacturer's instruction. qRT-PCR with a TB Green ${ }^{\mathrm{TM}}$ Premix Ex Taq ${ }^{\mathrm{TM}}$ II kit (Takara, Dalian, China) was performed using a MA-6000 RT-PCR System (Molarray, Suzhou, China). The qRT-PCR reaction conditions were as following: $95^{\circ} \mathrm{C}$ for $30 \mathrm{~s}$, followed by 40 cycles of $95^{\circ} \mathrm{C}$ for $5 \mathrm{~s}$, and $60^{\circ} \mathrm{C}$ for $1 \mathrm{~min}$. The expression levels of each gene were determined according to the $2^{-\triangle \Delta C T}$ method (Livak \& Schmittgen, 2001). Three biological replicates were used. The BvACTIN gene was used as the internal control. All the primers of nine $B v W R K Y$ genes used for qRT-PCR are listed in Table 1.

\section{Phenotype analysis}

To further determine the effects of alkaline stress on phenotype of sugar beet, four-week-old seedlings were treated with the above alkaline concentrations for $7 \mathrm{~d}$. At the end of treatments, samples of shoots and roots were separated and collected, respectively. Fresh weights (FW) of 
212 shoots and roots were assayed immediately. Dry weights (DW) of shoots and roots samples were

213 determined after oven drying at $80{ }^{\circ} \mathrm{C}$ until constant weight. Each treatment consisted of eight

214 biological replicates. Two seedlings were pooled in each replicate. Data were analyzed by using

215 one-way analysis of variance (ANOVA) at a significant level of $P<0.05$.

\section{RESULTS}

217

\section{Identification and characterization of the $B v W R K Y$ genes}

A total of 64 transcripts in the sugar beet genome sequences is identified as possible candidate members of the WRKY family. After removing the incomplete sequences without the conserved WRKY domain, a total of 58 sequences are eventually identified as the putative sugar beet $W R K Y$ genes and named as $B v W R K Y 1$ to $B v W R K Y 58$ according to their order in the sugar beet genomic sequence (Supplementary Table $\mathrm{S} 2$ ). The sequence analysis of the $B v W R K Y$ genes showed that CDS ranges from $558(B v W R K Y 24)$ to 2,307 bp (BvWRKY18) and predicted proteins ranged from 185 to 768 amino acids (aa) in length with an average of approximately 387 aa. The MWs varied from 21.3 ( $B v W R K Y 24)$ to $84.2 \mathrm{kDa}(B v W R K Y 18)$. The pIs ranged from 5.4 (BvWRKY7) to 9.9 (BvWRKY19), with $22 \mathrm{pIs}>7$ and the remaining $\mathrm{pIs} \leq 7$ (Supplementary Table S2).

\section{Classification and phylogenetic analysis of the $B v W R K Y$ genes}

To determine the structural features of each BvWRKY protein, multiple sequences alignments were performed by using DNAMAN 6.0 (Supplementary Fig. S1). Of the 58 BvWRKY proteins identified, the majority $(47,81 \%)$ had one conserved WRKYGQK domain, and remaining 11 (19\%) contained two conserved WRKYGQK domains (Supplementary Fig. S1 and Table S2). Although the WRKYGQK domain was absolutely conserved in the WRKY families, two proteins (BvWRKY7 and -8) differed at one residue, with a glutamine (Q) being replaced by a lysine $(\mathrm{K})$ residue; similar change is also observed in other plant species such as barley (Mangelsen et al., 2008), tomato (Huang et al., 2012) and sesame (Sesamum indicum) (Li et al., 2017). Furthermore, all the BvWRKY proteins contained the $\mathrm{C}-\mathrm{X}_{4-7}-\mathrm{C}-\mathrm{X}_{22-23}-\mathrm{H}$ motif that forms zinc-finger structures of $\mathrm{C}_{2} \mathrm{HC}$ or $\mathrm{C}_{2} \mathrm{H}_{2}$.

To explore the phylogenetic and evolutionary relationship of the $W R K Y$ genes in sugar beet and group them with the established subfamilies, we investigated 118 amino acid sequences containing the conserved WRKYGQK domain. These sequences consisted of 58 sequences from 
242 sugar beet and 60 sequences from Arabidopsis (Supplementary Table S1). An unrooted NJ

243 phylogenetic tree was constructed according to multiple alignments of the predicted amino acid

244

245

246

247

248

249

250

251

252

253

254

255

256 sequences by MEGA 7.0 (Fig. 1). According to WRKY classification in Arabidopsis (Eulgem et al., 2000), the $58 B v W R K Y$ genes were clustered into three major groups I, II, and III. There are 11 members in the $B v W R K Y$ group I, 40 members in group II, and 7 members in group III. Moreover, the $B v W R K Y s$ in group II were subdivided into five subgroups IIa, b, c, d, and e, containing 3, 7, 15, 7, and 8 members, respectively (Fig. 1 and Supplementary Table S2).

\section{Chromosomal distribution of the BvWRKY genes and their genomic duplication}

To examine the genomic distribution of the $W R K Y$ genes, the $B v W R K Y$ genes were mapped on their corresponding chromosome by searching the released genomic database of sugar beet. The results showed that $55 B v W R K Y$ genes are unevenly distributed on nine sugar beet chromosomes (Fig. 2), and the number on each chromosome is not necessarily correlated with its length. Chr 2, 5, and 6 had relatively more $B v W R K Y$ genes, with 9, 11, and 9 genes, respectively. Chr 3 and 7 contained relatively fewer $B v W R K Y$ genes, with only 3 genes, respectively (Fig. 3a). The other 3 genes ( $B v W R K Y 56,-57$, and -58) were mapped onto unassembled scaffolds based on the current database (Supplementary Table S2). The BvWRKY genes density per chromosome ranged from $0.071 / \mathrm{Mb}$ to $0.234 / \mathrm{Mb}$ (Fig. 3b). Averagely, one $B v W R K Y$ gene was present every 6.53 $\mathrm{Mb}$. Several chromosomes have higher densities of $B v W R K Y$ genes compared to others. Chr 2 has the highest density of $B v W R K Y$ genes, whereas Chr 7 has the lowest density (Fig. 3b).

Two or more homologous genes within a $100 \mathrm{~Kb}$ range distance were defined as tandem duplicates. Nine tandem duplication regions clustered with $19 \mathrm{BvWRKY}$ genes, including 3 genes in group I, 2 genes in group IIa, 2 genes in group IIb, 6 genes in group IIc, 2 genes in group IId, and 4 genes in group IIe, are identified on Chr 2 (BvWRKY7 and -8, and BvWRKY 10, -11, -12), Chr 5 (BvWRKY28, -29), Chr 6 (BvWRKY34, -35 and BvWRKY37, -38), Chr 8 (BvWRKY46, -47 and $B v W R K Y 49,-50)$, and Chr 9 (BvWRKY52, -53 and BvWRKY54, -55), respectively (Fig. 2). The segmental duplications were further analyzed on $100 \mathrm{~kb}$ DNA segments flanking each $B v W R K Y$ gene and no gene was found to be attributed to segmental duplication. Therefore, it is speculated that tandem duplication most likely played an important role in the observed gene expansion of sugar beet $W R K Y$ genes.

\section{Conserved motifs and structure of the $B v W R K Y$ genes}

To further examine the structural characteristics of the WRKY genes in sugar beet, the 
conserved motifs of BvWRKY proteins were predicted by using the MEME 5.0.5 and further annotated by using InterPro Scan 5.0 (Jones et al., 2014). A total of 10 putatively conserved motifs were identified in the BvWRKY proteins (Fig. 4). The identified amino acids length of BvWRKY motifs varied from 15 to 50. Detailed sequences of BvWRKY motifs are shown in Supplementary Fig. S2. The number of motifs was different in those proteins, varying from two to six. The results showed that motif 1 and -3 were annotated as WRKY domains, while motif 2 was found in the zinc-finger domain. Notably, similar motif compositions were observed in the same group of BvWRKY proteins. Motif 3 and -6 were found in group I and motif 7 in the IIa and IIb subgroups (Fig. 4).

To determine the structural diversity of the $B v W R K Y$ genes, the distribution of intron-exon was analyzed and compared. The number of exons in BvWRKYs ranged from 2 (BvWRKY3, -6, $23,-24,-26$, and -39$)$ to $6(B v W R K Y 10,-11,-12,-18,-22,-40,-49,-50,-57$, and -58$)$. It was found that $53.4 \%$ of $B v W R K Y$ genes contained the typical splicing of three exons and two introns (Fig. 5). For members of group II, the IIa subgroup contained 4 exons, subgroup IIb contained $2-$ 6 exons, the IIc and IId subgroups contained 3 exons, and subgroup IIc contained 2-4 exons (Fig. 5). These results suggested that $B v W R K Y$ genes displayed the diversity of intron/exon structure.

\section{GO analysis of $B v W R K Y$ genes}

To reveal the functional classifications of the $B v W R K Y$ genes, GO terms were predicted by using online tool DAVID 6.8. The results showed that the $B v W R K Y$ genes were categorized into 7 functional groups under main three categories: cellular component, biological process and molecular function (Fig. 6 and Supplementary Table S2). More genes were classified under "sequence-specific DNA binding (GO:0043565)" and "transcription factor activity (GO:0003700)" than the five other functional groups, such as "transcription regulatory region DNA binding (GO:0031347)", "regulation of defense response (GO:0031347)”, "positive regulation of transcription (GO:0045893)", "nucleus (GO:0005636)" and cytoplasm “GO: 0005737” (Fig. 6 and Supplementary Table S2).

\section{D structure prediction of BvWRKY proteins}

To understand the structural characteristics of BvWRKY proteins, 3D structures were constructed according to the similar template obtained from PDB using I-TASSER. The modeled structures for the selected BvWRKY proteins contained 3 (BvWRKY3) to 58 (BvWRKY42) $\alpha$ - 
helices and 19 (BvWRKY42) to 38 (BvWRKY10) $\beta$-strands (Fig. 7 and Supplementary Fig. S3). All the predicted BvWRKY models showed a C-score range from -2.57 to -4.44 (Supplementary Table S3), indicating that the predicted proteins are constructed with high accuracy.

\section{Expression analysis of $9 \mathrm{BvWRKY}$ genes in response to alkaline stress}

To further confirm if the expression of $B v W R K Y$ genes was induced by alkaline stresses, 9 genes, namely $B v W R K Y 3,-10,-16,-22,-41,-42,-44,-47$, and -51 , were selected according to homologous genes in rice and Arabidopsis which play the vital roles in abiotic stresses (Wu et al., 2005), and qRT-PCRs were performed to analyze their expression pattern in response to different concentrations of $\mathrm{NaCHO}_{3}$. The results showed that the expression patterns of the most detected $B v W R K Y$ genes differed in response to alkaline stresses (Fig. 8 and Supplementary Table S4). With the increase of $\mathrm{NaCHO}_{3}$ concentrations, the transcript abundances of three genes $(B v W R K Y 10,-42$, and -47) in shoots gradually increased at 15 and $25 \mathrm{mM}$, then reached a maximum value at $50 \mathrm{mM}$ which are 3.2-, 1.7- and 1.6-fold of those at control $(0 \mathrm{mM})$, respectively, and then either maintained a higher level (BvWRKY10 and -42) or showed a significant reduction (BvWRKY47) at $100 \mathrm{mM}$ (Fig. 8b, f, h). Additionally, the expression levels of $B v W R K Y 3$ or $B v W R K Y 51$ in shoots were unchanged or repressed by alkaline stresses compared with control. It is also showed that the expression levels of both $B v W R K 16$ and -42 in roots displayed a significant enhancement at $25 \mathrm{mM}$, then reached a peak value at $50 \mathrm{mM}$ which are 12.6- and 1.4-fold higher than those at control, respectively, and then exhibited a reduction at $100 \mathrm{mM}$ (Fig. 8c, f). Interestingly, two genes (BvWRKY22 and -41) showed a down-, up- and then down-regulation pattern in shoots (Fig. 8d, e), whereas other genes (BvWRKY44 and -51) displayed an up-, down- and then up-regulation pattern in roots with the increase of alkaline concentrations (Fig. 8g, i). These results demonstrated that sugar beet WRKYs expression patterns vary in response to alkaline stresses.

\section{Phenotype analysis of sugar beet under alkaline stress}

To further understand alkaline tolerance of sugar beet, shoots and roots of seedlings were harvested at $7 \mathrm{~d}$ after different concentrations of $\mathrm{NaHCO}_{3}$ treatments. The results showed that additional $15 \mathrm{mM} \mathrm{NaHCO}_{3}$ significantly increased fresh weight (FW), but not dry weight (DW) in shoot compared with control $(0 \mathrm{mM})$, while concentrations of 25-100 mM had no significant effects on both FW and DW in shoot. Compared to control, all concentrations of $\mathrm{NaHCO}_{3}$ did not have any effects on either FW or DW in roots (Supplementary Fig. S4 and Table S5). These 
results suggested that sugar beet displays strongly tolerant to alkaline stress.

\section{DISCUSSION}

The $W R K Y$ family has been widely identified in various organisms, including spike mosses, single-celled green algae, slime molds and protozoa (Rushton et al., 2010). In monocots and dicots, including soybean (Glycine max) (Luo et al., 2013), wheat (Qin, Tian \& Liu, 2015), rice (Dai, Wang \& Zhang, 2016), and cotton (Gossypium hirsutum) (Liu et al., 2016), an especially large number of $W R K Y$ genes have been documented to have various functions in recent years. In the present study, the $W R K Y$ genes were firstly identified from whole-genome sequences of sugar beet.

To date, whole genomes of many plants have been sequenced and a large of the WRKY genes have been identified in various plant species (Wu, 2005; Wei et al., 2012; Dou et al., 2014; Yu et al., 2016; Yue et al., 2016; Jing et al., 2017). Completion of the sugar beet genome makes it possible to analyze the WRKY genes at the whole genome level (Dohm et al., 2014). In the present study, a total of 58 putative $B v W R K Y$ genes are identified in the sugar beet genome (Supplementary Table S2). It was found that there are $32 \mathrm{WRKY}$ genes in broomcorn millet (Panicum miliaceum) (Yue et al., 2016), 71 in sesame (Li et al., 2017), 85 in cassava (Manihot esculenta) (Wei et al., 2016), 88 in common bean (Phaseolus vulgaris) (Jing et al., 2016), 100 in rice (Wu, 2005), 103 in Aegilops tauschii (Ma et al., 2014), 116 in Gossypium raimondii (Dou et al., 2014), and 136 in maize (Wei et al., 2012). These findings suggested that there are large differences in number of the $W R K Y$ genes families among various plant species.

These are consistent with the classification of the $W R K Y$ family genes in many plant species such as Arabidopsis (Eulgem et al., 2000), maize (Wei et al., 2012), Populus (Jiang et al., 2014), cassava (Wei et al., 2016), and peach (Prunus persica) (Chen et al., 2016). All the $W R K Y$ genes can be classified into three distinct clusters: group I, II, and III depending on the number of conserved WRKY regions and the pattern of zinc-finger motif (Eulgem et al., 2000; Wei et al., 2012; Jiang et al., 2014). There are evidences that genes of group I included double conserved WRKY domains, which can interact with the W-box "TTGACC/T" core motif to activate downstream genes, and $\mathrm{C}_{2} \mathrm{H}_{2}$ zinc-finger motif; group II only possessed single WRKY domain and shared the same zinc-finger motif as group I; whereas group III had one conserved WRKY domain and $\mathrm{C}_{2} \mathrm{HC}$ zinc-finger motif (Eulgem et al., 2000; Rushton et al., 2010). In this study, 11, 40, and $7 B v W R K Y$ genes have been classified into groups I, II, and III based on Eulgem et al. 
366 (2000) and by using the WRKY proteins in Arabidopsis as references, respectively (Fig. 1 and 367 Supplementary Table S2). Although the WRKYGQK domain was considered to be highly conserved in the WRKY family, tow proteins (BvWRKY7 and BvWRKY8) in group II differed at one residue, with a glutamine being changed into a lysine $(\mathrm{K})$ residue (Supplementary Fig. $\mathrm{S} 1$ ). This change has been found in many plant species such as barley (Mangelsen et al., 2008) and tomato (Huang et al., 2012). Furthermore, previous studies have documented that group III was the largest group of $W R K Y$ genes families in rice and broomcorn millet, which accounted for 38\% and 50\% (Ross, Liu \& Shen, 2010; Yue et al., 2016), while in Arabidopsis and sesame, group II was the largest group, accounting for 24\% and 68\% (Eulgem et al., 2000; Li et al., 2017), respectively. In the present study, group II has been also found to be the largest group of $W R K Y$ genes family in sugar beet, accounting for $69 \%$ of all the $B v W R K Y$ genes, which are consistent with the results of Arabidopsis and sesame but different from rice and broomcorn millet. Moreover, group II can be divided into five distinct subgroups IIa, b, c, d, and e, according to the amino acid sequences outside the WRKY domain (Fig. 1 and Supplementary Table S2). Subgroup IIc is also found to be the largest subgroup, accounting for $37.5 \%$ of all the genes of group II (Supplementary Table S2), which is in accordance with the results reported in soybean (Luo et al., 2013), Arabidopsis (Qin et al., 2015), rice (Dai et al., 2016), and cotton (Liu et al., 2016). Additionally, there are closely evolutionary relationships between group IIa and IIb, and between group IId and IIe (Fig. 1), respectively, which appear to make up monophyletic clades. Additionally, according to the distance of phylogenetic relationship, three groups of the $B v W R K Y$ genes can be clustered in four major lineages: group IIc + I, group IId + IIe, group III, and group IIa + IIb, respectively (Fig. 1). Similar lineages were also found in the MdWRKY genes families from apple (Lui et al., 2017). These results further confirmed that the WRKY family genes are highly conserved family in different plant species.

Gene duplication events played critical roles in rapid expansion and the evolution of genes families (Cannon et al., 2004). It is well-known that genes within a single genome are divided into five distinct classes: singletons, dispersed-, proximal-, tandem- and segmental/whole genome duplication (WGD)-duplicates, respectively, according to the copy number of genes and the distribution of genome (Wang et al., 2012). It was documented that duplication events can lead to a clustered occurrence of family members via tandem amplification, or a scattered occurrence via segmental duplication of chromosomal regions (Grassi, Lanave \& Saccone, 
2008). In the present study, 32.8\% (19/58) of the $B v W R K Y$ genes likely evolved from tandem repeats (Fig. 2). Tandem gene replications of WRKYs have been found in Arabidopsis (Cannon et al., 2004), rice (Ross, Liu \& Shen, 2010), cucumber (Cucumis sativus) (Ling et al., 2011), and soybean (Yu et al., 2016). However, it was found that no gene was attributed to segmental duplication in sugar beet $W R K Y$ genes. Therefore, it is proposed that tandem duplication might be major attributor in the expansion of the $B v W R K Y$ genes in sugar beet.

The number of motifs in $B v W R K Y s$ ranges from 2 to 6, and the length of motifs varied from 15 to 50 amino acids (Fig. 4 and Supplementary Fig. S2). In addition, 4 motifs (motif 1, -2, -3, and -6) are found in the WRKY DNA-binding domain. Similar motifs compositions were reported in SiWRKYS from sesame (Li et al., 2017). The other 6 motifs are found to be located outside in the WRKY domain. It is clear that motif 1 and -2 are shared by all the $B v W R K Y$ genes, while motif 3 and -6 were shared by 11 genes, viz BvWRKY10, -11, -12, -14, -18, -22, -40, -41, 44, -45, and -51 (Fig. 4), which belonged to members of group I (Supplementary Table S2). Importantly, motif 5, $-7,-8$, and -9 were shared by members of group II, and motif 10 was shared by group I. It is clear that members of $W R K Y$ family in the same cluster commonly shared similar motif compositions in sugar beet genome.

The structural diversity of exon/intron, an important part in the evolution of gene families, provides an additional evidence supporting phylogenetic classification (Bleecker, 2003; Wang et al., 2014). In the present study, the number of introns found in the $B v W R K Y$ genes ranges from 1 to 5, with an average of 2.79 introns per $B v W R K Y$ gene, so each sequence of $B v W R K Y$ was divided into many segments by introns. Similarly, all the WRKY genes in both cassava and peach have 1-5 introns (Wei et al., 2006; Chen et al., 2016). However, the SiWRKY genes in sesame have 1-11 introns ( $\mathrm{Li}$ et al., 2017). These results implied that the $W R K Y$ genes showed the diversity of structures in various plant species. Moreover, the largest fraction of $B v W R K Y_{S}(27$, $46.6 \%$ ) have 2 introns (Fig. 5), which is common in other plant species, including cassava (42 of 85) (Wei et al. 2006), peach (29 of 58) (Chen et al., 2016), and sesame (33 of 71) (Li et al., 2017).

Alkaline is one of the most serious abiotic stresses that limits plant growth and crop productivity in the arid and semi-arid regions of Northern China (Guo, Shi \& Wang, 2010). However, few alkaline tolerant genes have been identified in sugar beet. Recent researches have demonstrated that the $W R K Y$ genes are involved in various abiotic stresses, especially salt stress 
428 (Zhou et al., 2015; Liang et al., 2017; Lui et al., 2017; Wang et al., 2017; Wu et al., 2017). There 429 are evidences that a majority of $W R K Y S$ were remarkably up-regulated only by salinity in various

430

431

432

433

434

435

436

437

438

439

440

441

442

443

444

445

446

447

448

449

450

451

452

453

454

455

456

457

458 plant species, such as cucumber (Ling, Wang \& Jiang, 2011) and tomato (Huang et al., 2012). In

$B$. distachyon, however, the most $B d W R K Y$ genes were significantly down-regulated by various abiotic stresses (Wen et al., 2014). In this study, the detected $B v W R K Y$ genes showed a variety of expression patterns in shoots and roots of sugar beet seedlings under various concentrations of $\mathrm{NaHCO}_{3}$ (Fig. 8). When plants are exposed to alkaline stress, the expression levels of $B v W R K Y 10,-42$ and -47 in shoots slowly raised at 15 and $25 \mathrm{mM}$, then reached a peak value at $50 \mathrm{mM}$, and then either maintained a higher level (BvWRKY10 and -42) or showed a significant decrease (BvWRKY47) at $100 \mathrm{mM}$ (Fig. 8b, f, h). Similarly, BvWRK16 and BvWRKY42 in roots displayed the same expression pattern. It was also observed that $B v W R K Y 3$ and -51 in shoots were unchanged and down-regulated by all the concentrations of alkaline (Fig. 8a, i). However, four genes ( $B v W R K Y 22$ and -41 in shoots, or $B v W R K Y 44$ and -51 in roots) responded to alkaline stress in an irregular pattern (going down, up and then down, or doing up, down and then up with the increase of alkaline concentrations) (Fig. 8d, e, g, i). This expression pattern might be attributed to the variety of the $B v W R K Y$ genes transcription. Importantly, the mRNA levels of $B v W R K Y 10$ in shoots and $B v W R K Y 16$ in roots were 2.2- and 12.6-fold higher at $50 \mathrm{mM} \mathrm{NaHCO}_{3}$ than those at control condition $(0 \mathrm{mM})($ Fig. $8 \mathrm{~b}, \mathrm{c})$. Additionally, GO analysis showed that most of the $B w W R K Y$ genes are classified into functional groups of "sequence-specific DNA binding (GO:0043565)" and "transcription factor activity (GO:0003700)" (Fig. 6 and Supplementary Table S2). These results implied that these $B v W R K Y$ genes might positively respond to alkaline stress via binding to $\mathrm{W}$-boxes (TTGACC/T) of in the promoter regions of downstream genes related to alkaline tolerance (Rushton et al., 2010). However, their detailed functions in alkaline tolerance of sugar beet need to be further addressed by using chromatin immunoprecipitation (ChIP), RNA interference, gene overexpression or editing methods. Overall, our results provide useful information for studying the effects of the $B v W R K Y$ genes in sugar beet under alkaline stress.

\section{CONCLUSION}

In the present study, a total of 58 putative $B v W R K Y$ genes were identified in the sugar beet genome. Based on the primary amino acid sequence, the $B v W R K Y$ genes are classified into three major groups I, II, and III, each with 11, 40, and 7 genes, respectively. $B v W R K Y$ genes of group

Peer) reviewing PDF | (2019:06:38143:3:0:NEW 27 Aug 2019) 
459 II are further divided into five distinct subgroups IIa, b, c, d, and e, containing 3, 7, 15, 7, and 8 460 members, respectively. All the identified BvWRKY proteins have one or two conserved WRKY domains and one zinc-finger structure. The number of introns in the $B v W R K Y$ genes range from 1 to 5 , with the majority of $B v W R K Y s$ containing 3 exons. Furthermore, the detected $B v W R K Y$ genes showed a variety of expression patterns in shoots and roots of seedling exposed to alkaline stress. Notably, the transcript levels of BvWRKY10 in shoots and BvWRKY16 in roots are significantly higher at $50 \mathrm{mM}$ alkaline than those at control condition. This study provides a wide identification of the $B v W R K Y$ genes, and would be helpful for the improvement of alkaline tolerance in sugar beet by genetic engineering.

\section{ACKNOWLEDGEMENTS}

We would like to thank Mr. Shengfu Duan for kindly providing seeds of sugar beet. We are very grateful to Prof. Jin-Lin Zhang from Lanzhou University for critically reviewing the manuscript and for valuable suggestions. We are also thankful to two reviewers for their constructive comments on the manuscript.

\section{ADDITIONAL INFORMATION AND DECLARATIONS}

\section{Funding}

This work was supported by the National Natural Science Foundation of China (No. 31860404) and the Natural Science Foundation of Gansu Province (No. 18JR3RA152). The funders had no role in study design, data collection and analysis, decision to publish, or preparation of the manuscript.

\section{Competing Interests}

The authors declare that they have no competing interests.

\section{Author Contributions}

- Guo-Qiang Wu conceived and designed the experiments, prepared the figures and/or tables, drafted the work or revised it critically for important content, approved the final draft.

- Zhi-Qiang Li performed the experiments, analyzed the data, prepared the figures and/or tables, approved the final draft.

- Han Cao and Jin-Long Wang performed the experiments, approved the final draft.

\section{Supplementary Information}


Dataset S1 Effects of alkaline stress on $\mathrm{Na}^{+}$and $\mathrm{K}^{+}$concentration in sugar beet seedlings. Figure S1 Multiple sequences alignments of BvWRKYs domain.

Figure S2 Detailed information of BvWRKY motifs in sugar beet.

Figure S3 Details of secondary structure of BvWRKY proteins.

Figure S4 Effects of alkaline stress on fresh and dry weights of sugar beet.

Table S1 Details of sequences of the WRKY genes from sugar beet and Arabidopsis.

Table S2 Identification of $B v W R K Y$ genes using sugar beet genome data.

Table S3 Structural dependent modeling parameters for the BvWRKY proteins.

Table S4 Expression data of the BvWRKY genes.

Table S5 Phenotypic data in sugar beet after 7 days of alkaline stress treatments.

\section{REFERENCES}

Bailey TC, Elkan C. 1994. Fitting a mixture model by expectation maximization to discover motifs in biopolymers. Proceedings of the Second International Conference on Intelligent Systems for Molecular Biology 2: 28-36.

Bechtold U, Field B. 2018. Molecular mechanisms controlling plant growth during abiotic stress. Journal of Experimental Botany 69(11): 2753-2758.

Benkert P, Biasini M, Schwede T. 2011. Toward the estimation of the absolute quality of individual protein structure models. Bioinformatics 27: 343-350.

\section{Berman HM, Westbrook J, Feng Z, Gilliland G, Bhat TN, Weissig H, Shindvalov IN,} Bourne PE. 2000. The Protein Data Bank. Nucleic Acids Research 28: 235-242.

Bleecker SAB. 2003. Expansion of the receptor-like kinase/pelle gene family and receptor-like proteins in Arabidopsis. Plant Physiology 132(2): 530-543.

Cannon SB, Mitra A, Baumgarten A, Young ND, May G. 2004. The roles of segmental and tandem gene duplication in the evolution of large gene families in Arabidopsis thaliana. BMC Plant Biology 4(1):10.

Cao H, Wang L, Nawaz MA, Niu ML, Sun JY, Xie JJ, Kong QS, Huang Y, Cheng F, Bie ZL. 2017. Ectopic expression of pumpkin $N A C$ transcription factor $C m N A C l$ improves multiple abiotic stress tolerance in Arabidopsis. Frontiers in Plant Sciences 8: 2052.

Chen M, Tan Q, Sun M, Li DM, Fu XL, Chen XD, Xiao W, Li L, Gao DS. 2016. Genomewide identification of WRKY family genes in peach and analysis of WRKY expression during bud dormancy. Molecular Genetics and Genomics 291(3): 319-1332. 
Chinnusamy V, Zhu J, Zhu JK. 2006. Gene regulation during cold acclimation in plants. Physiologia Plantarum 126(1): 52-61.

Dai X, Wang Y, Zhang WH. 2016. Os $W R K Y 74$, a $W R K Y$ transcription factor, modulates tolerance to phosphate starvation in rice. Journal of Experimental Botany 67(3): 947-960.

Dan Z, Hou L, Xiao P, Guo Y, Michael K, Deyholos, Liu X. 2018. $V v W R K Y 30$, a grape $W R K Y$ transcription factor, plays a positive regulatory role under salinity stress. Plant Science 280(3): 132-142.

Dohm JC, Minoche AE, Daniela H, Salvador CG, Falk Z, Hakim T, Oliver R, Thomas Rosleff S, Ralf S, Richard R, Alexander G, Thomas K, Britta S, Stadler PF, Schmidt T, Gabaldón T, Lehrach H, Weisshaar B, Himmelbauer H. 2014. The genome of the recently domesticated crop plant sugar beet (Beta vulgaris). Nature 505: 546-552.

Dou L, Zhang X, Pang C, Song MZ, Wei HL, Fan SL, Yu SX. 2014. Genome-wide analysis of the WRKY gene family in cotton. Molecular Genetics and Genomics 289(6): 1103-1121.

Eulgem T, Rushton PJ, Robatzek S, Somssich IE. 2000. The WRKY superfamily of plant transcription factors. Trends in Plant Science 5(5): 199-206.

Gasteiger E, Hoogland C, Gattiker A, Duvaud S, Wilkins MR, Appel RD, Bairoch A. 2005. Protein identification and analysis tools on the ExPASy Server; (In) John M. Walker (ed): The Proteomics Protocols Handbook, Humana Press pp: 571-607.

Grassi AD, Lanave C, Saccone C. 2008. Genome duplication and gene-family evolution: The case of three $O X P H O S$ gene families. Gene 421(1-2): 1-6.

Guo LQ, Shi DC, Wang DL. 2010. The key physiological response to alkali stress by the alkali-resistant halophyte Puccinellia tenuiflora is the accumulation of large quantities of organic acids and into the rhyzosphere. Journal of Agronomy \& Crop Science 196(2): 123135.

Hasanuzzaman M, Nahar K, Alam M, Mahabub, Roychowdhury R. Fujita, M. 2013. Physiological, biochemical, and molecular mechanisms of heat stress tolerance in plants. International Journal of Molecular Sciences 14(5): 9643-9684.

He GH, Xu JY, Wang YX, Liu JM, Ma YZ, Xu ZS. 2016. Drought-responsive WRKY transcription factor genes TaWRKY1 and TaWRKY33 from wheat confer drought and/or heat resistance in Arabidopsis. BMC Plant Biology 16(1):116.

Hennig L. 2012. Plant gene regulation in response to abiotic stress. Biochim Biophys Acta 
550

551

552

553

554

555

556

557

558

559

560

561

562

563

564

565

566

567

568

569

570

571

572

573

574

575

576

577

578

579

580

1819(2):1.

Hu B, Jin JP, Guo AY, Zhang H, Luo JC, Gao G. 2015. GSDS 2.0: an upgraded gene feature visualization server. Bioinformatics 31(8): 1296-1297

Hu L, Liu S. 2012. Genome-wide analysis of the MADS-box gene family in cucumber. Genome 55: $245-256$.

Huang DW, Sherman BT, Lempicki RA. 2009. Bioinformatics enrichment tools: paths toward the comprehensive functional analysis of large gene lists. Nucleic Acids Research 37(1):113.

Huang S, Gao Y, Liu J, Peng X, Niu X, Fen Z, Cao S, Liu Y. 2012. Genome-wide analysis of WRKY transcription factors in Solanum lycopersicum. Molecular Genetics and Genomics 287(6): 495-513.

Ishiguro S, Nakamura K. 1994. Characterization of a cDNA encoding a novel DNA-binding protein, $S P F 1$, that recognizes $S P 8$ sequences in the 5' upstream regions of genes coding for sporamin and $\beta$-amylase from sweetpotato. Molecular \& General Genetics 244(6): $563-$ 571.

Jiang J, Ma S, Ye N, Jiang M, Cao J, Zhang J. 2016. $W R K Y$ transcription factors in plant responses to stresses. Journal of Integrative Plant Biology 59(2): 86.

Jiang Y, Duan Y, Yin J, Ye S, Zhu J, Zhang F, Lu W, Fan D, Luo K. 2014. Genome-wide identification and characterization of the Populus WRKY transcription factor family and analysis of their expression in response to biotic and abiotic stresses. Journal of Experimental Botany 65(22): 6629-6644.

Jiang Y, Gang L, Yu D. 2012. Activated expression of $W R K Y 57$ confers drought tolerance in Arabidopsis. Molecular Plant 5(6): 1375-1388.

Jing W, Jibao C, Lanfen W, Wang S. 2017. Genome-wide investigation of $W R K Y$ transcription factors involved in terminal drought stress response in common bean. Frontiers in Plant Science 8: 380 .

Jones P, Binns D, Chang HY, Fraser M, Li W, McAnulla C, McWilliam H, Maslen J, Mitchell A, Nuka G, Pesseat S, Quinn AF, Sangrador-Vegas A, Scheremetjew M, Yong SY, Lopez R, Hunter S. 2014. InterProScan 5: genome-scale protein function classification. Bioinformatics 30(9):1236-1240.

Khadiza K, Khan RAH, Park JI, Nath UK, Kimm KB, Nou IS, Chung MY. 2017. Molecular 
characterization and expression profiling of tomato $G R F$ transcription factor family genes in response to abiotic stresses and phytohormones. International Journal of Molecular Sciences 18(5): 1056.

Kotchoni SO, Kuhns C, Ditzer A, Kirch HH, Bartels D. 2006. Over-expression of different aldehyde dehydrogenase genes in Arabidopsis thaliana confers tolerance to abiotic stress and protects plants against lipid peroxidation and oxidative stress. Plant Cell \& Environment 29(6): 1033-1048.

Larkin MA, Blackshields G, Brown NP, Chenna R, Mcgettigan PA, Mcwilliam H, Valentin F, Wallace IM, Wilm A, Lopez R. 2007. Clustal W and Clustal X version 2.0. Bioinformatics 23(21): 2947-2948.

Lee SC, Lee MY, Kim SJ, Jun SJ, An G, Kim SR. 2005. Characterization of an abiotic stressinducible dehydrin gene, OsDhn1, in rice (Oryza sativa L.). Molecules \& Cells 19(2): 212218.

Li D, Liu P, Yu J, Wang L, Dossa K, Zhang Y, Zhou R, Wei X, Zhang X. 2017. Genomewide analysis of $W R K Y$ gene family in the sesame genome and identification of the WRKY genes involved in responses to abiotic stresses. BMC Plant Biology 17(1): 152.

Li S, Fu Q, Huang W, Yu D. 2009. Functional analysis of an Arabidopsis transcription factor WRKY25 in heat stress. Plant Cell Reports 28(4): 683-693.

Liang QY, Wu YH, Wang K, Bai ZY, Liu QL, Pan YZ, Zhang L, Jiang BB. 2017. Chrysanthemum WRKY gene DgWRKY5 enhances tolerance to salt stress in transgenic chrysanthemum. Scientific Reports 7(1): 4799.

Ling L, Jiang WJ, Zhang Y. 2011. Genome-wide analysis of $W R K Y$ gene family in Cucumis sativus L. BMC Genomics 12(1): 471.

Liu H, Wang Q, Yu M, Zhang YY, Wu YB, Zhang HX. 2010. Transgenic salt-tolerant sugar beet (Beta vulgaris L.) constitutively expressing an Arabidopsis thaliana vacuolar $\mathrm{Na}^{+} / \mathrm{H}^{+}$ antiporter gene, AtNHX3, accumulates more soluble sugar but less salt in storage roots. Plant Cell \& Environment 31(9): 1325-1334.

Liu X, Song Y, Xing F, Wang N, Wen F, Zhu C. 2016. GhWRKY25, a group I $W R K Y$ gene from cotton, confers differential tolerance to abiotic and biotic stresses in transgenic Nicotiana benthamiana. Protoplasma 253(5): 1265-1281.

Livak KJ, Schmittgen TD. 2001. Analysis of relative gene expression data using real time 
612

quantitative PCR and the $2^{-\Delta \Delta C T}$ method. Methods 25(4): 402-408.

Lui S, Luo C, Zhu L, Sha R, Qu S, Cai B, Wang S. 2017. Identification and expression analysis of $W R K Y$ transcription factor genes in response to fungal pathogen and hormone treatments in apple (Malus domestica). Journal of Plant Biology 60(2): 215-230.

Luo DL, Ba LJ, Shan W, Kuang JF, Lu WJ, Chen JY. 2017. Involvement of WRKY transcription factors in ABA-induced cold tolerance of banana fruit. Journal of Agriculture Food Chemistry 65(18): 3627-3635.

Luo X, Bai X, Sun X, Zhu D, Liu B, Ji W, Cai H, Cao L, Wu J, Hu M, Liu X, Tang L, Zhu Y. 2013. Expression of wild soybean WRKY20 in Arabidopsis enhances drought tolerance and regulates ABA signaling. Journal of Experimental Botany 64(8): 2155-2169.

Ma J, Zhang D, Shao Y, Liu P, Jiang L, Li C. 2014. Genome-wide analysis of the WRKY transcription factors in Aegilops tauschii. Cytogeneti \& Genome Research 144(3): 243-253.

Mangelsen E, Kilian J, Berendzen KW, Kolukisaoglu H, Harter K, Jansson C. 2008. Phylogenetic and comparative gene expression analysis of barley (Hordeum vulgare) WRKY transcription factor family reveals putatively retained functions between monocots and dicots. BMC Genomics 9(1): 194.

Potter SC, Luciani A, Eddy SR, Park Y, Lopez R, Finn RD. 2018. HMMER web server: 2018 update. Nucleic Acids Research 46(W1): W200-W204.

Prachi P, Vadivelmurugan I, Bagavathiannan MV, Senthil M. 2017. Impact of combined abiotic and biotic stresses on plant growth and avenues for crop improvement by exploiting physio-morphological traits. Frontiers in Plant Science 8: 537.

Qin Y, Tian Y, Liu X. 2015. A wheat salinity-induced WRKY transcription factor TaWRKY93 confers multiple abiotic stress tolerance in Arabidopsis thaliana. Biochemical and Biophysical Research Communications 464(2): 428-433.

Ross CA, Liu Y, Shen QJ. 2010. The WRKY gene family in rice (Oryza sativa). Journal of Integrative Plant Biology 49(6): 827-842.

Rushton PJ, Somssich IE, Ringler P, Shen QJ. 2010. WRKY transcription factors. Trends in Plant Science 15(5): 247-258.

Sharma M, Kumar R, Solanke A, Sharma R, Tyagi AK, Sharma AK. 2010. Identification, phylogeny, and transcript profiling of $E R F$ family genes during development and abiotic stress treatments in tomato. Molecular Genetics \& Genomics 284(6): 455-475. 
Song Y, Jing S, Zhang L, Yu D. 2010. Overexpression of $O s W R K Y 72$ gene interferes in the abscisic acid signal and auxin transport pathway of Arabidopsis. Journal of Biosciences 35: $459-471$.

Ulker B, Somssich IE. 2004. $W R K Y$ transcription factors: from DNA binding towards biological function. Current Opinion in Plant Biology 7(5): 491-498.

Wang K, Wu YH, Tian XQ, Bai ZY, Liang QY, Liu QL, Pan YZ, Zhang L, Jiang BB. 2017. Overexpression of DgWRKY4 enhances salt tolerance in Chrysanthemum seedlings. Frontiers in Plant Science 8:1592.

Wang L, Zhu W, Fang L, Sun X, Su L, Liang Z, Wang N, Londo JP, Li S. 2014. Genomewide identification of $W R K Y$ family genes and their response to cold stress in Vitis vinifera. BMC Plant Biology 14(1): 103.

Wang Y, Tang H, Debarry JD, Tan X, Li J, Wang X, Lee T, Jin H, Marler B, Guo H, Kissinger JC, Paterson AH. 2012. MCScanX: a toolkit for detection and evolutionary analysis of gene synteny and collinearity. Nucleic Acids Research 40(7): e49.

Wei KF, Chen J, Chen YF, Wu LJ, Xie DX. 2012. Molecular phylogenetic and expression analysis of the complete $W R K Y$ transcription factor family in maize. DNA Research 19(2): $153-164$.

Wei Y, Shi H, Xia Z, Tie W, Ding Z, Yan Y, Wang W, Hu W, Li K. 2016. Genome-wide identification and expression analysis of the $W R K Y$ gene family in cassava. Frontiers in Plant Science 7: 25.

Wen F, Zhu H, Li P, Jiang M, Mao W, Ong C, Chu Z. 2014. Genome-wide evolutionary characterization and expression analyses of WRKY family genes in Brachypodium distachyon. DNA Research 21(3): 327-339.

Wu GQ, Liang N, Feng RJ, Zhang JJ. 2013. Evaluation of salinity tolerance in seedlings of sugar beet (Beta vulgaris L.) cultivars using proline, soluble sugars and cation accumulation criteria. Acta Physiologiae Plantarum, 35(9): 2665-2674.

Wu GQ, Feng RJ, Liang N, Yuan HJ, Sun WB. 2015. Sodium chloride stimulates growth and alleviates sorbitol-induced osmotic stress in sugar beet seedlings. Plant Growth Regulation, 75(1): 307-316.

Wu KL. 2005. The WRKY family of transcription factors in rice and Arabidopsis and their origins. DNA Research 12(1):9-26. 
Wu M, Liu H, Han G, Cai R, Pan F, Xiang Y. 2017. A moso bamboo $W R K Y$ gene $P e W R K Y 83$ confers salinity tolerance in transgenic Arabidopsis plants. Scientific Reports 7(1):11721.

Yang Y, Guo Y. 2018. Elucidating the molecular mechanisms mediating plant salt-stress responses. New Phytologist 217(2): 523-539.

Yang J, Yan R, Roy A, Xu D, Poisson J, Zhang Y. 2015. The I-TASSER Suite: Protein structure and function prediction. Nature Methods 12: 7-8.

Yu Y, Wang N, Hu R, Xiang F. 2016. Genome-wide identification of soybean $W R K Y$ transcription factors in response to salt stress. Springerplus 5(1): 920.

Yue H, Chang X, Zhi Y, Wang L, Xing G, Song W, Nie X. 2019. Evolution and identification of the WRKY gene family in quinoa (Chenopodiun quinoa). Genes, 10: 131.

Yue H, Wang M, Liu S, Du X, Song W, Nie X. 2016. Transcriptome-wide identification and expression profiles of the $W R K Y$ transcription factor family in broomcorn millet (Panicum miliaceum L.). BMC Genomics 17: 343.

Zhang H, Mao X, Jing R, Chang X, Xie H. 2011. Characterization of a common wheat (Triticum aestivum L.) TaSnRK2.7 gene involved in abiotic stress responses. Journal of Experimental Botany 62(3): 975-988.

Zheng W, Zhang C, Wuyun Q, Pearce R, Li Y, Zhang Y. 2019. LOMETS2: improved metathreading server for fold-recognition and structure-based function annotation for distanthomology proteins. Nucleic Acids Research, 47: W429-W436.

Zhou L, Wang NN, Gong SY, Lu R, Li Y, Li XB. 2015. Overexpression of a cotton (Gossypium hirsutum) WRKY gene, GhWRKY34, in Arabidopsis enhances salt-tolerance of the transgenic plants. Plant Physiology Biochemistry 96: 310-320.

Zhu X, Liu S, Meng C, Qin L, Kong L, Xia G. 2013. $W R K Y$ transcription factors in wheat and their induction by biotic and abiotic stress. Plant Molecular Biology Reporter 31(5): 10531067. 


\section{Figure 1}

Phylogenetic tree of WRKY genes in sugar beet (Beta vulgaris, Bv) and Arabidopsis thaliana $(A t)$.

The predicted proteins sequences of 58 BVWRKYs and 60 AtWRKYs were aligned by the Clustal W and the phylogenetic tree was constructed using the MEGA7.0 by the NJ method with 1,000 bootstrap replicates. The WRKY genes were clustered into three major groups. AtWRKYs and BVWRKYs are represented in orange circles and blue squares, respectively. Details of sequences of BVWRKYs and AtWRKYs are listed in Supplementary Table S1. 


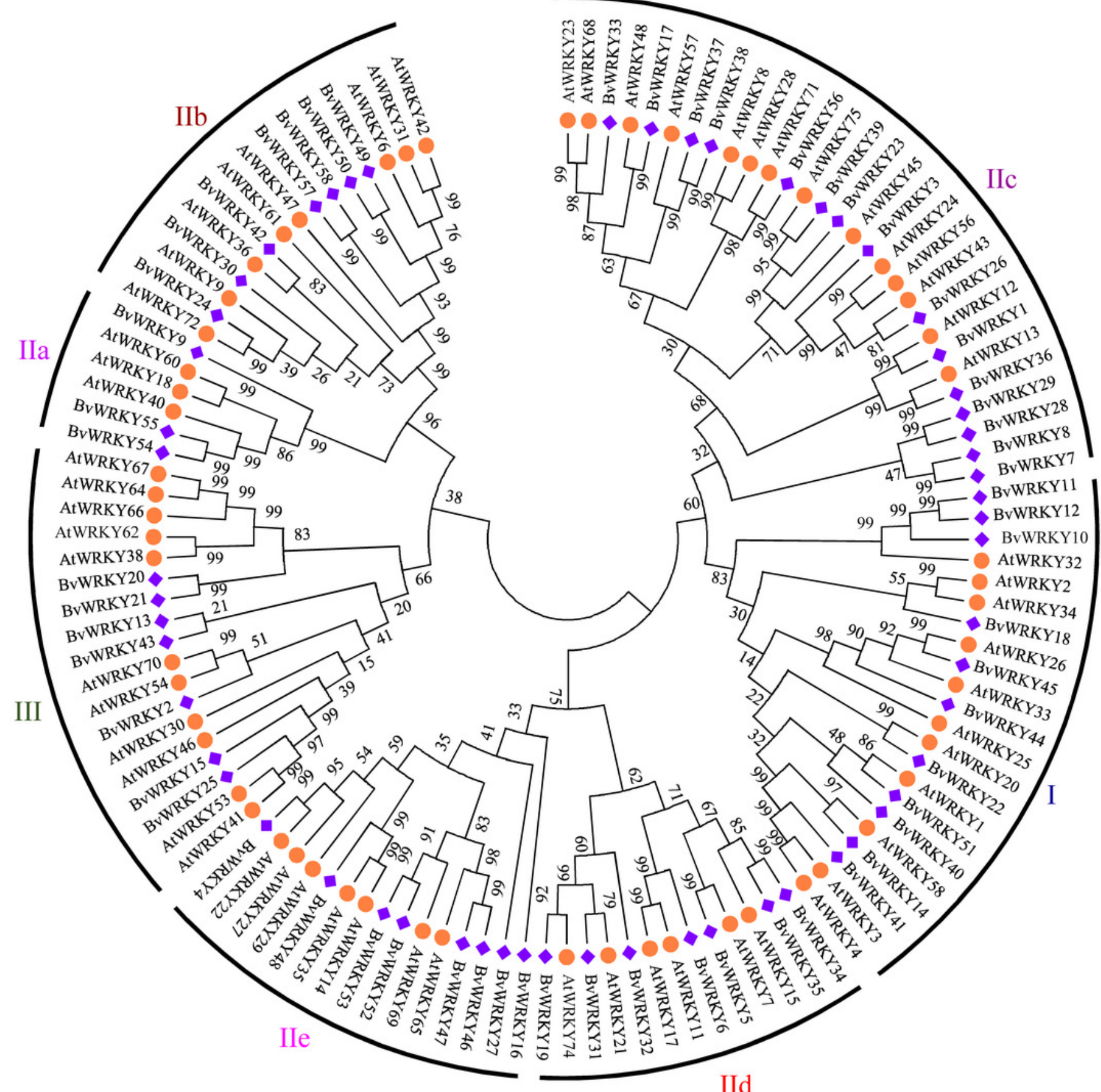


Figure 2

Distribution of the BVWRKY genes on the sugar beetchromosomes.

The chromosome number is indicated at the top of each chromosome. The scale of the genome size is given on the left. Red lines represent tandem gene duplications.

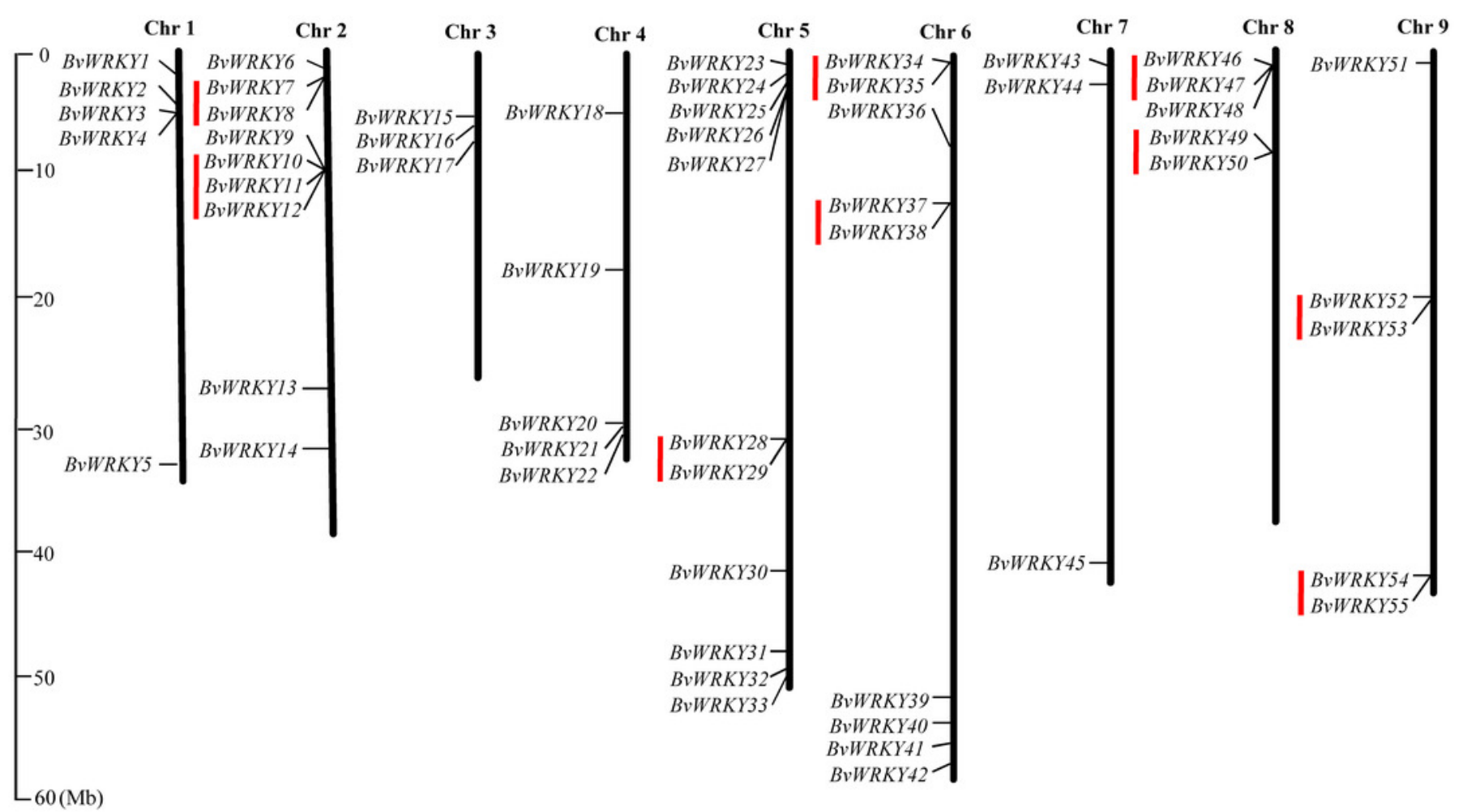


Figure 3

Unevenly chromosomal distributionof the BVWRKY genes.

(a) Number of BVWRKY genes in each chromosome. (b) The BVWRKY genes density per chromosome.
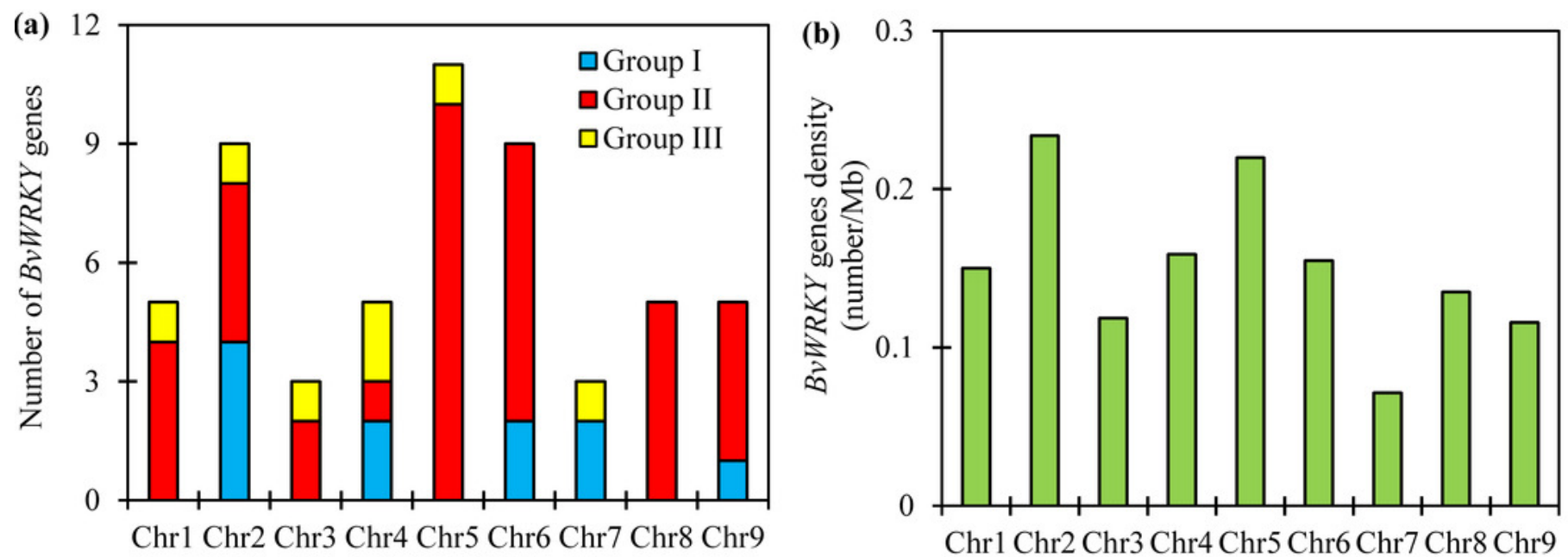
Figure 4

BVWRKY proteins motifs identified by MEME using the complete amino acid sequences.

Combined $p$-values are indicated and different motifs are shown by different colors and numbered from 1 to 10. Detailed information of BVWRKY motifs is listed in Supplementary Figure S2. 

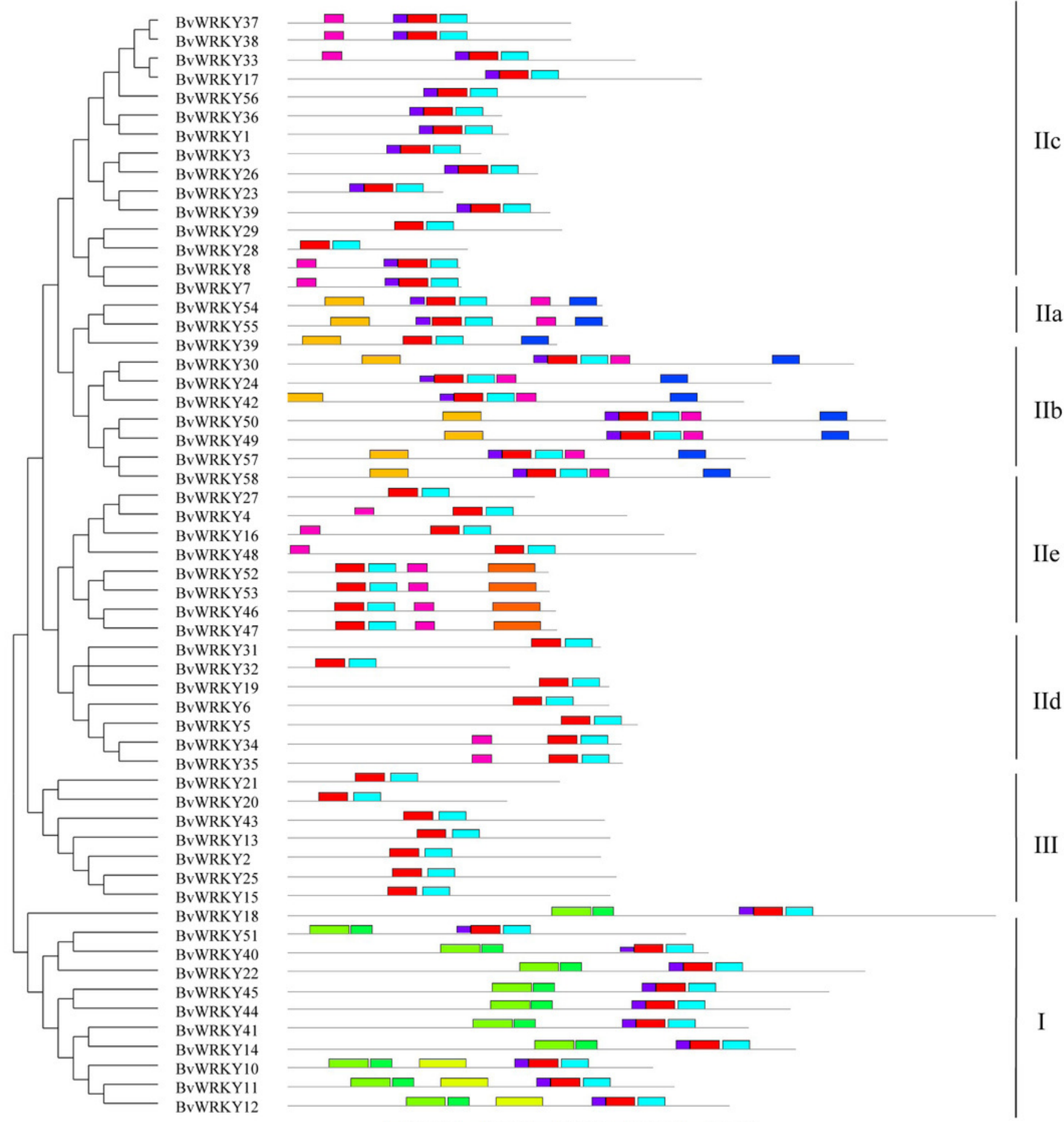

$\mathrm{IIb}$

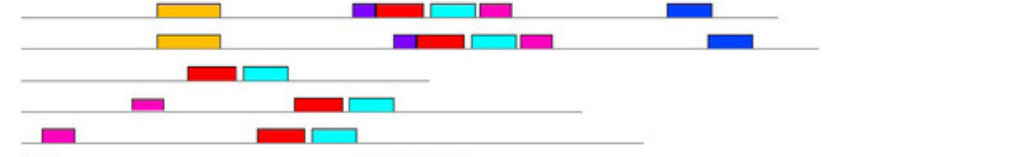

Ic

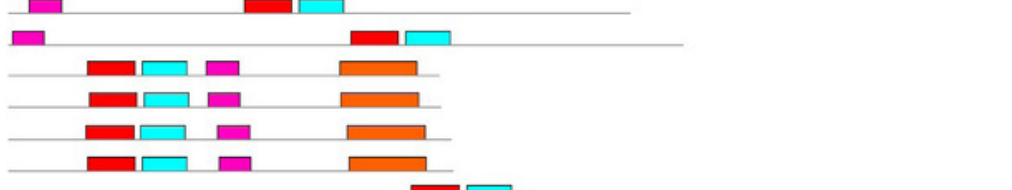

IIe
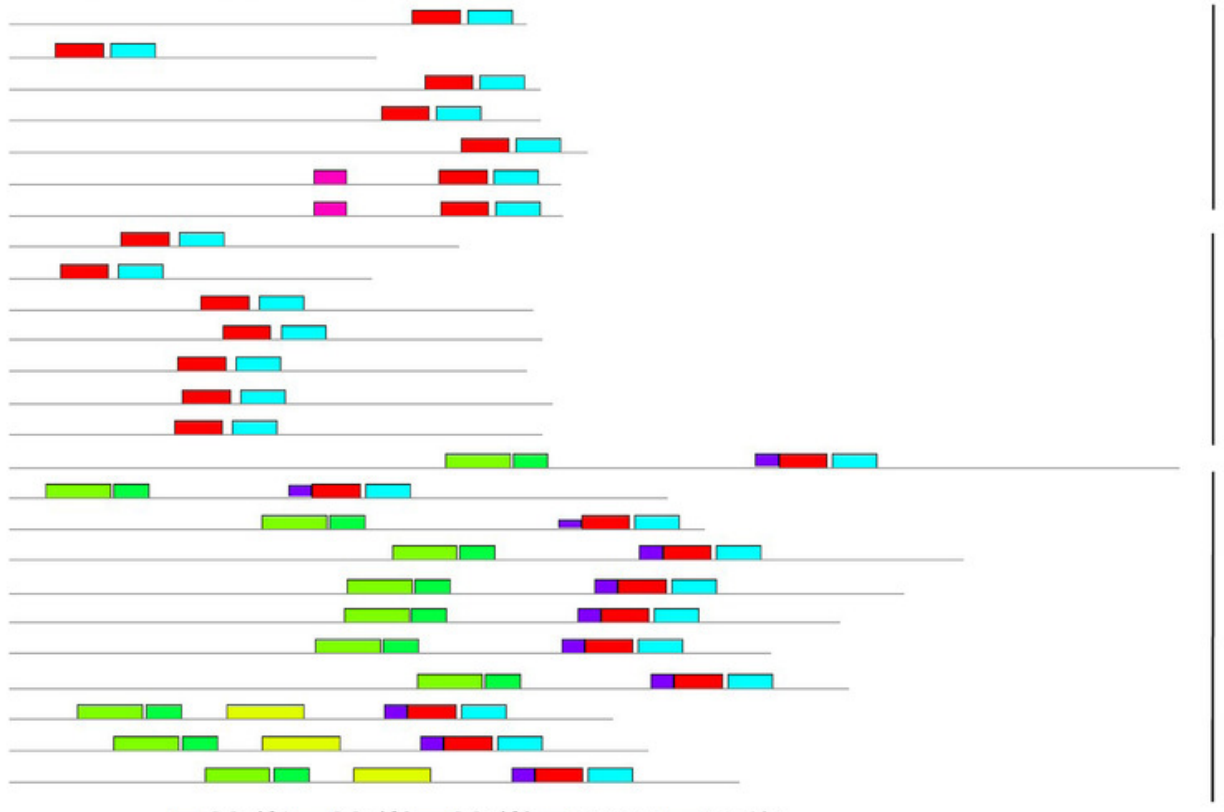

Motif $1=$ Motif $2=$ Motif $3=$ Motif $4=$ Motif 5

Motif $6-$ Motif $7=$ Motif 8- Motif 9- Motif 10 


\section{Figure 5}

The exon-intron structures of the BvWRKY genes.

Exon-intron structure analyses of the BVWRKY genes were performed by using the online tool GSDS. Lengths of exons and introns of each BvWRKY gene were exhibited proportionally. Introns are represented by black lines. Exons are represented by yellow boxes. UTR are represented by blue boxes. The scale of genes length is given at the bottom. CDS: Coding equence; UTR: Untranslated region. 


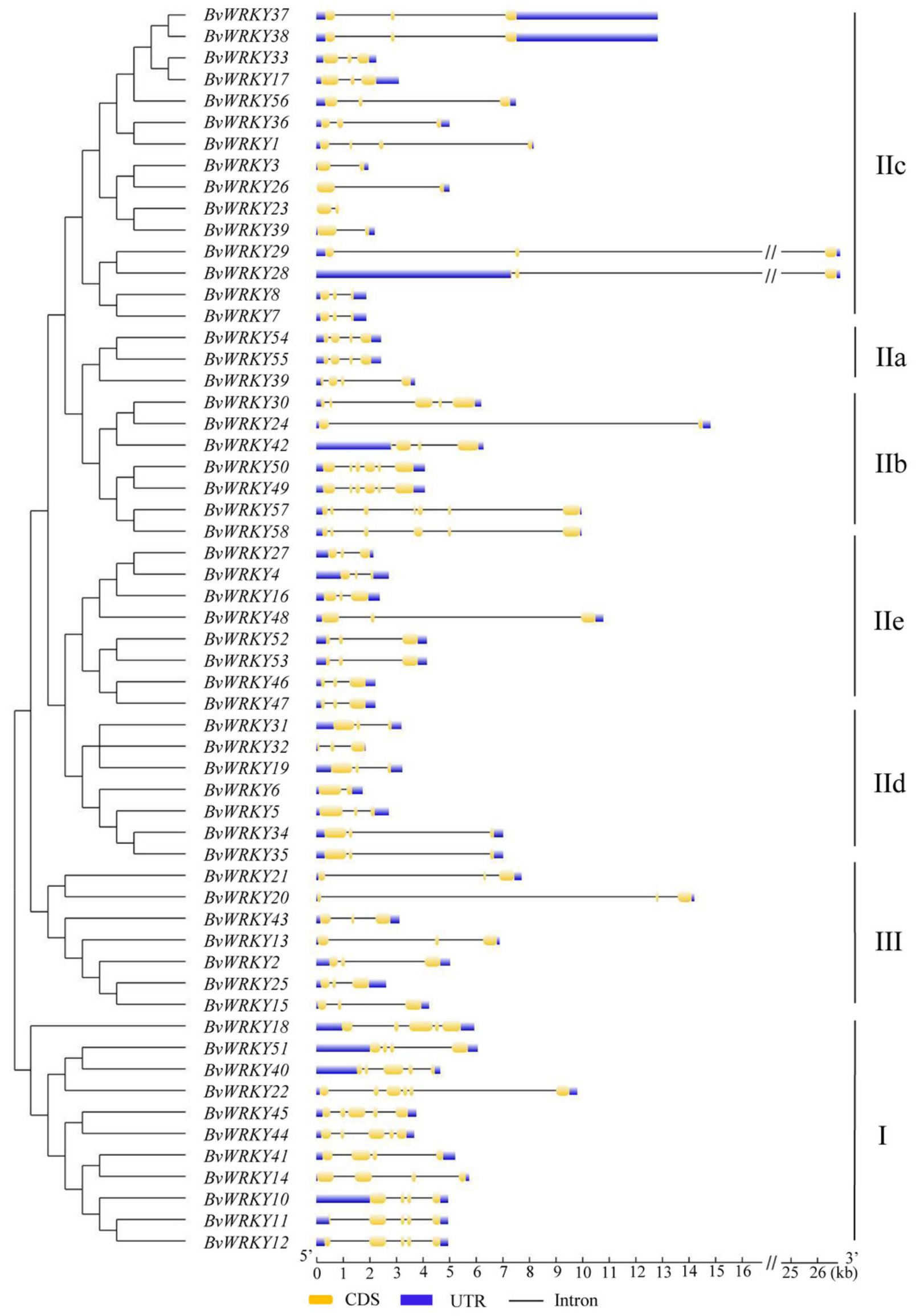




\section{Figure 6}

Gene ontology (GO) analysis of the BvWRKY genes.

The lengths of the rectangular columns indicate the number of genes that participated in the corresponding classification. Categories pertaining to cellular component, molecular function and biological process were defined by GO classification.

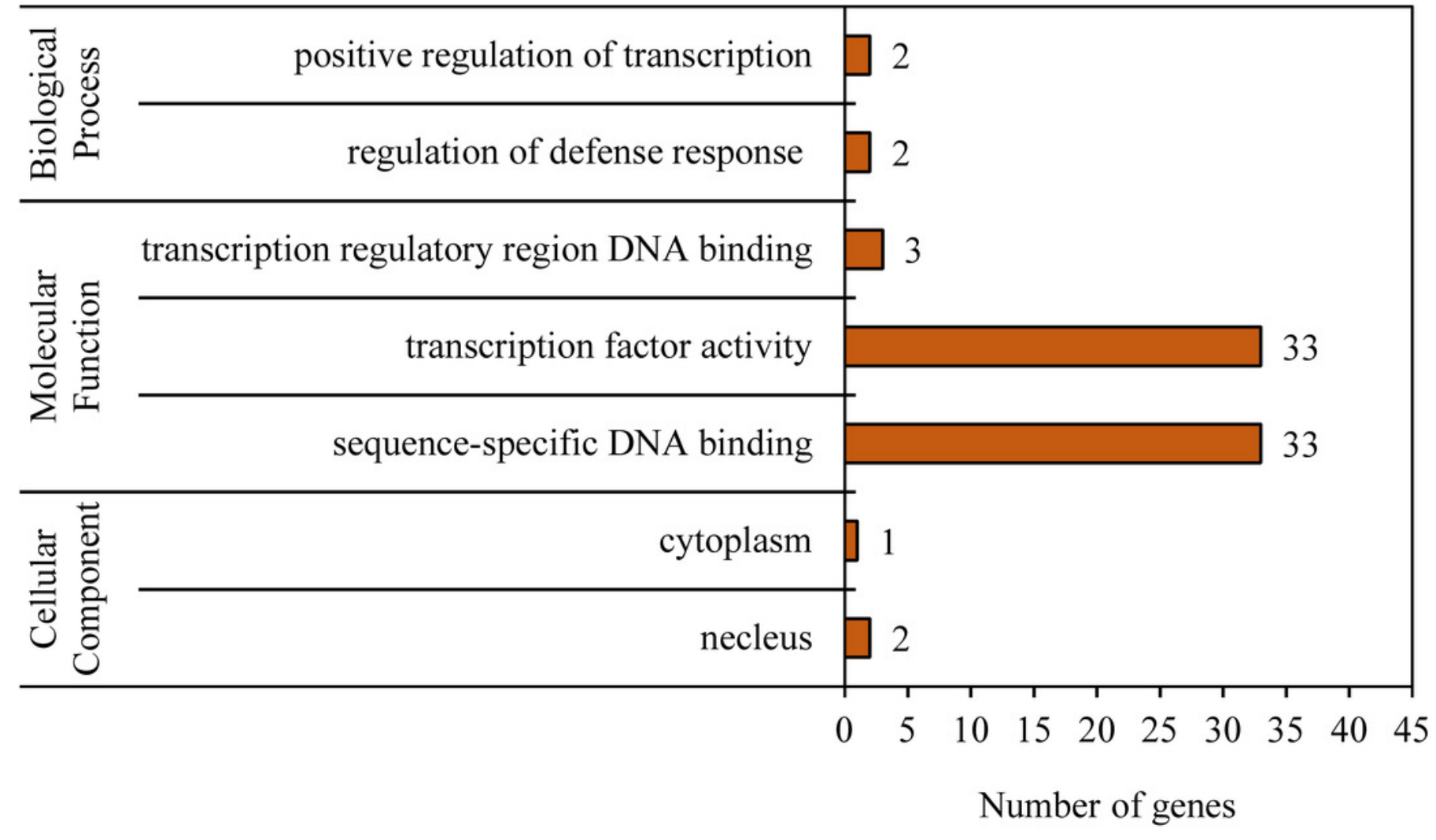




\section{Figure 7}

\section{Predicted three-dimensional (3D) structure of nine selected BvWRKY proteins.}

(a) BvWRKY3; (b) BvWRKY10; (c) BvWRKY16; (d) BvWRKY22; (e) BvWRKY41; (f) BvWRKY42; (g) BvWRKY44; (h) BvWRKY47; (i) BvWRKY51. The models were gained by I-TASSER. $\alpha$-helices, $\beta$-strands and random coils are shown in red, yellow and blue, respectively. The best Protein Data Bank (PDB) structural analog for each protein is shown in Supplementary Table S3. Details of secondary structure of BwWRKY proteins are represented in Supplementary Figure S3. 


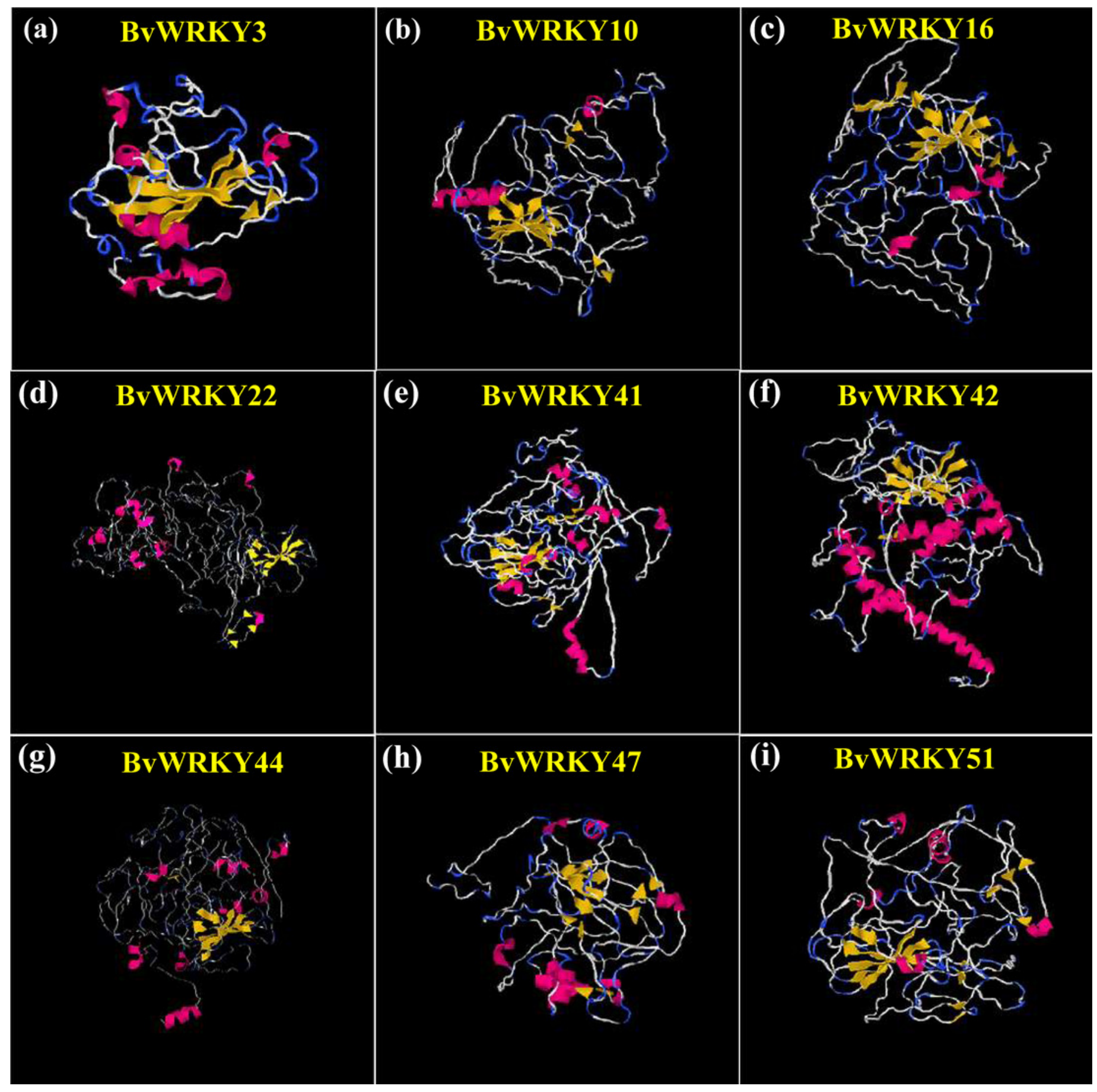




\section{Figure 8}

Relative expression levels of nine selected BVWRKY genes in shoot and root of sugar beet seedlings exposed to $0,15,25,50$, and $100 \mathrm{mM} \mathrm{NaHCO}_{3}$ for $72 \mathrm{~h}$.

(a) BVWRKY3; (b) BVWRKY10; (c) BvWRKY16; (d) BvWRKY22; (e) BvWRKY41; (f) BvWRKY42; (g) BvWRKY44; (h) BvWRKY47; (i) BvWRKY51. Expression of the BvWRKY genes normalized to those of BVACTIN and shown relative to the expression at $0 \mathrm{mM} \mathrm{NaHCO}_{3}$. The $2^{-\Delta \Delta \mathrm{Ct}}$ method was used to calculate the expression levels of target genes at different treatments. Experiments were repeated at least three times. Values are means \pm SE and bars indicate SE $(n=3)$. Columns with different letters indicate significant differences at $P<0.05$ (Duncan's test). 

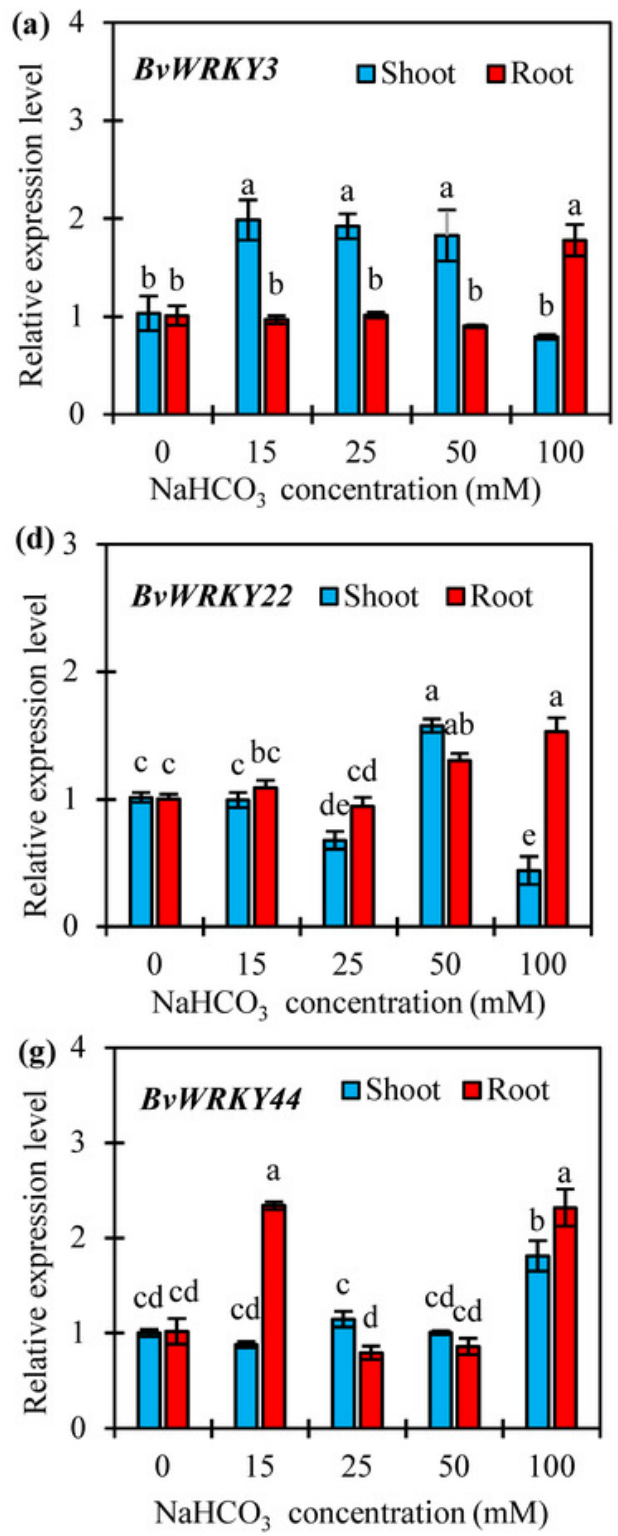
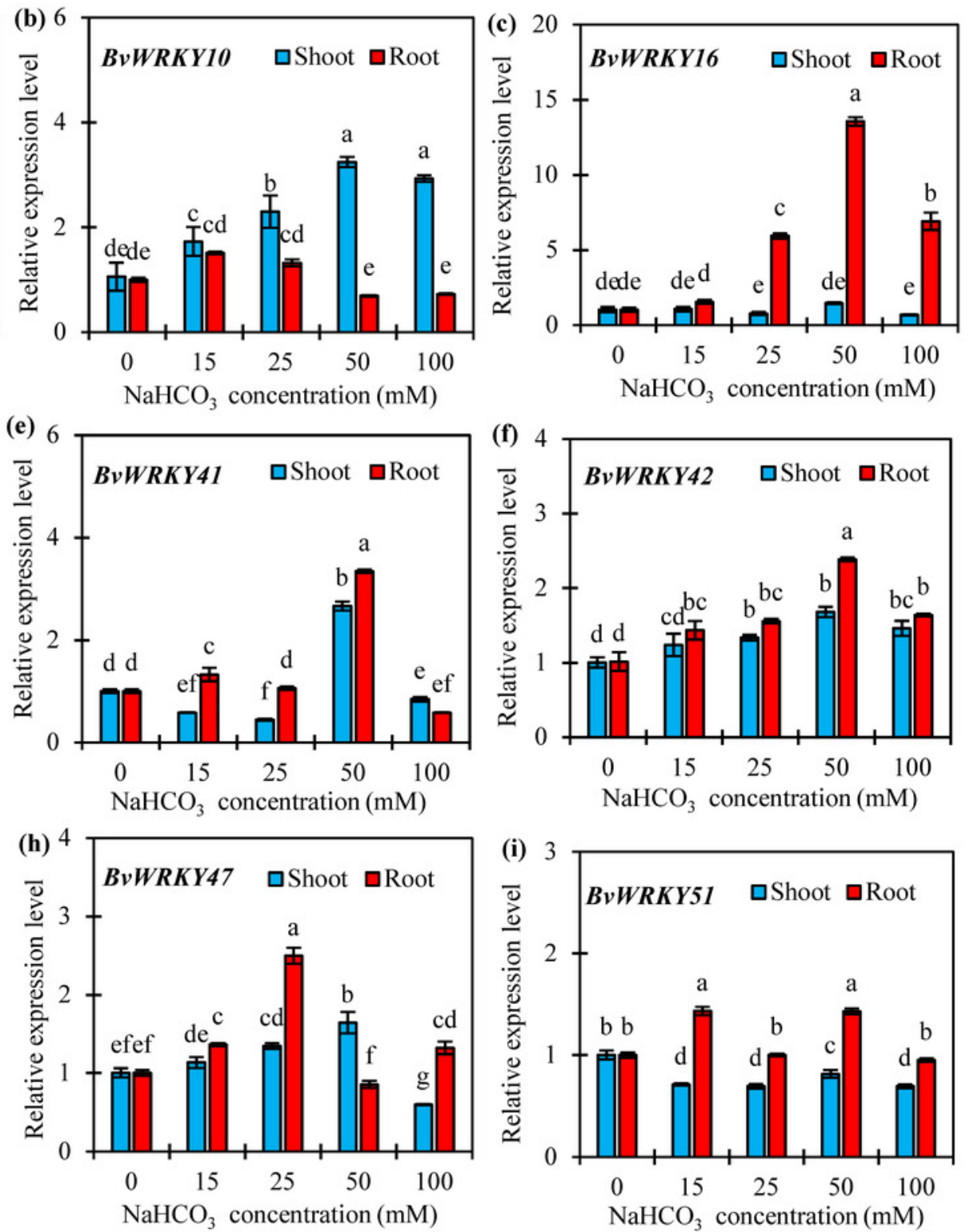


\section{Table 1 (on next page)}

Sequences of primers used in qRT-PCR. 


\begin{tabular}{llll}
\hline No. & Gene name & Forward primer sequence (5'-3') & Reverse primer sequence (5'-3') \\
\hline 1 & $B v A C T I N$ & ACTGGTATTGTGCTTGACTC & ATGAGATAATCAGTGAGATC \\
2 & $B v W R K Y 3$ & CCTCATGGATGAACTACAAAACGTCG & ATCAACGGCATCCGAAACGTTAATC \\
3 & $B v W R K Y 10$ & CTCCAGATGATGTTCCAAGGACAC & GGCACAGCAAGAAAGAGAAGTG \\
4 & $B v W R K Y 16$ & CGGCTACCACTAGACTTAGCTCCT & GTCTTTAAGCTCATCTTGTGACGTGC \\
5 & $B v W R K Y 22$ & CTCAACCTAATCGCCGACTTC & ATTAAATGGAGGCACGCGGT \\
6 & $B v W R K Y 41$ & CGGAAAATCTCACAACTCCCTCTTCT & TTCGGAGAAGAAACTCGAGACCAG \\
7 & $B v W R K Y 42$ & GGAGACCGAGATCAGTGGTTCTTC & TACTTCTCCCATCTTTGCTTTGGC \\
8 & $B v W R K Y 44$ & GGCTCCTTCTTCACTTTCTGTCTC & CCACCAAATGCTCCTACAGTTG \\
9 & $B v W R K Y 47$ & CTACCTCAAGCTAGCATGGAAGCAA & TCTTAGGAGATGATATGGAGGCGGC \\
10 & $B v W R K Y 51$ & GCAGTGATTGTAGCTCCTAAGGTT & ATGGTTTCTCAGGGACAACAGA \\
\hline
\end{tabular}

